\title{
AZUL DE METILENO E SEUS BENEFÍCIOS DIANTE DOS TRANSTORNOS MENTAIS E DOENÇAS NEURODEGENERATIVAS
}

\author{
Pedro Henrique Pereira Guerra*1, Kleber Alves Gomes ${ }^{2}$, Mariane Costa Santos de Tavares ${ }^{3}$, \\ Marco Antônio Pereira Guerra4, Lucas Barandas Souza5, Isabela Barandas Souza5, Valdir Rubi \\ Ecke Junior5, Otávio Benedito Rodrigues Guerra da Silva5, João Lucas Pereira Aguiar6, Luiz \\ Fernando Pereira Ribeiro7 ${ }^{7}$ Carolina Pereira Veloso ${ }^{8}$, Déborah Junia Pereira Aguiar8 \\ and Ana Flávia Pereira Guerra ${ }^{9}$
}

1Discente do Curso de Graduação em Medicina, Faculdades Santo Agostinho, Vitória da Conquista - BA, Brasil; ${ }^{2}$ Biólogo. Mestre em Genética e Biologia Molecular pela Universidade Estadual de Santa Cruz, Doutor em Biotecnologia pela Universidade de SãoPaulo - USP. Docente do Curso de Graduação em Medicina Faculdades Santo Agostinho, Vitória da Conquista -BA, Brasil; ${ }^{3}$ Fisioterapeuta. Especialista em Fisioterapia Respiratória e Terapia Intensiva pelas Faculdades Integradas Pitágoras, Discente do Curso de Graduação em Medicina Faculdades Santo Agostinho, Vitória da Conquista - BA, Brasil; ${ }^{4}$ Discente do Curso de Graduação em Medicina, Centro Universitário das Faculdades Associadas - SP, Brasil; 5Discente do Curso de Graduação em Medicina, Universidade de Franca, Franca - SP, Brasil; 6Discente do Curso de Graduação em Medicina, Centro Universitário UNIFG, Guanambi - BA, Brasil; ${ }^{7}$ Discente do Curso de Graduação em Medicina,

Centro Universitário Unifaminas, Muriaé- MG, Brasil; ${ }^{8}$ Discente do Curso de Graduação em Medicina, Centro Universitário Atenas, Paracatu - MG, Brasil; ${ }^{9}$ Fisioterapeuta. Bacharel em fisioterapia pelas Faculdades Pitágoras, Belo Horizonte - MG, Brasil

\section{ARTICLE INFO}

\section{Article History:}

Received $17^{\text {th }}$ January, 2021

Received in revised form

$08^{\text {th }}$ February, 2021

Accepted $06^{\text {th }}$ March, 2021

Published online $13^{\text {th }}$ April, 2021

\section{Key Words:}

Azul de metileno. Transtornos mentais. Doença de Alzheimer. Neuroproteção.

*Corresponding author:

Pedro Henrique Pereira Guerra

\begin{abstract}
Os transtornos mentais são síndromes que causam nos pacientes, quadros de sofrimento ou quadros de incapacidade mental e/ou biológica, de maneira que prejudicam uma adequação social desses pacientes. São característicos alterações na cognição, no emocional, no comportamento levando uma queda nos processos psicológicos e/ou biológicos. Acerca desses transtornos sabe-se que, dentro de uma cascata de transdução neuronal, cada receptor molecular que é responsável por uma mensagem química e molecular é também um local potencial de alterações que gerarão a doença mental. Esses locais também são os alvos para substâncias psicotrópicas que surtirão um efeito neurofisiológico terapêutico. $\mathrm{O}$ azul de metileno é um corante orgânico que tem uma grande variedade de uso para ciência, sendo usado como corante citológico e composto antimalárico. Devido a capacidade do corante ser um aceptor de elétrons isso o torna um antioxidante potente e sua propriedade de atravessar a barreira hematoencefálica o torna um bom neuroprotetor. Estudos já realizados, levam à pontos bem delineados quanto a sua alta capacidade antioxidante, no entanto estudos acerca do efeito desse composto frente a doenças mentais são raros. O objetivo deste estudo foi identificar e descrever aplicabilidades desse composto nas áreas psiquiátricas e neurocientíficas. Trata-se de uma revisão integrativa de literatura, cuja busca por estudos se deu nas bases vinculadas à National Library of Medicine (PubMed) e à Biblioteca Virtual em Saúde (BVS). Os descritores em ciências da saúde (DECS) utilizados para busca foram: methylene blue, mental disorders e neuroprotection. Há poucos artigos na literatura que trata do uso de azul de metileno como um medicamento para transtornos mentais mas atualmente tem-se chamado atenção o uso do MB como possível tratamento para doenças neurológicas como doença de Parkinson e doença de Alzheimer. Apesar dos poucos estudos sobre esse composto como método terapêutico, os estudos que são feitos sobre ele, mostram resultados favoráveis a novas pesquisas do corante como terapia para transtornos mentais e doenças neurodegenerativas.
\end{abstract}

Copyright@2021, Pedro Henrique Pereira Guerra et al, 2021. This is an open access article distributed under the Creative Commons Attribution License, which permits unrestricted use, distribution, and reproduction in any medium, provided the original work is properly cited.

Citation: Pedro Henrique Pereira Guerra, Kleber Alves Gomes, Mariane Costa Santos de Tavares, Marco Antônio Pereira Guerra, Lucas Barandas Souza, Isabela Barandas Souza, Valdir Rubi Ecke Junior, Otávio Benedito Rodrigues Guerra da Silva et al. 2021. "Overview of engineering fire protection solutions in structures ", International Journal of Development Research 11, (04), 45936-45939. 


\section{INTRODUCTION}

Manual Diagnóstico e Estatístico de Transtornos Mentais, o DSM-5, protocolo no qual os profissionais da área da saúde tomam por referência ao diagnosticar doenças mentais, classifica um transtorno mental como uma síndrome, que tem por características: uma alteração clinicamente relevante na cognição; uma desregulação emocional ou uma alteração no comportamento do indivíduo, levando o paciente à uma queda da função de processos psicológicos, biológicos ou até mesmo de desenvolvimento que são subjacentes ao funcionamento mental. Os transtornos mentais estabelecidos causam, em grande parte desses pacientes, quadros de sofrimento ou incapacidades mentais e/ou biológicas que incidem na adequação social, nos padrões tidos como normais em um profissional de qualquer área, e em outras atividades importantes na vida diária desses pacientes (AMERICAN PSYCHIATRIC ASSOCIATION, 2013, p.20). Azul de metileno (MB) é um composto orgânicofenotiazínico, descoberto em 1876 por Heinrich Caro, sendo usado inicialmente como corante citológico, posteriormente mostrou suas funções terapêuticas passando a ser utilizado como um composto antimalárico e já no final do século XIX, antes da descoberta dos barbitúricos, teve utilidade em pacientes com quadros de agitação psicótica. $\mathrm{O} \mathrm{MB}$ tem ainda seu uso em outras áreas da medicina como no envenenamento por cianeto, uso no tratamento de intoxicação aguda por monóxido de carbono, em pacientes com metemoglobinemia, em pacientes com quadro de choque séptico e é usado também como antisséptico urinário. $\mathrm{O}$ uso do azul de metileno em tratamentos de doenças psiquiátricas como pacientes com transtorno de humor e atualmente o uso desse composto em pacientes com Doença de Alzheimer (DA) tem despertado cada vez mais atenção da sociedade científica (ALDA, 2019; BERROCAL et al., 2018).

O azul de metileno tem como característica ser altamente lipofílico permitindo-o atravessar a barreira hematoencefálica em grande concentração, devido a essa característica, ao administrar o MB, por via intravenosa ou por via oral, a biodisponibilidade do corante no cérebro é muito alta. Através desse mecanismo o azul de metileno pode exercer funções terapêuticas em sítios cerebrais e atualmente há estudos voltados para possíveis benefícios como: melhoria no declínio cognitivo pelo envelhecimento, ação terapêutica na neurodegeneração pela disfunção mitocondrial, ação retardatória na progressão da DA, ação neuroprotetora em neurônios dopaminérgicos da substância nigra em pacientes com Doença de Parkinson (DP) (BERROCAL et al., 2018; SMITH et al., 2017). Os transtornos mentais apresentam uma condição clínica de grande impacto na vida do paciente e por consequência impacta também a sociedade como um todo. A maioria desses transtornos tem uma abordagem terapêutica que resolvem parcialmente o problema do paciente uma vez que esse paciente pode ficar o resto da vida dependendo dessas substâncias terapêuticas. Tendo isso em mente é necessário ter sempre estudos que produzam novas abordagens terapêuticas para esses pacientes. O azul de metileno por ser um composto a muito tempo descoberto e de baixo custo, quando utilizado como forma terapêutica em transtornos mentais apresenta suas particularidades e seus benefícios. Em tal contexto o objetivo deste estudo foi identificar e descrever os benefícios farmacológicos do azul de metileno frente aos transtornos mentais e às doenças neurodegenerativas.

\section{MATERIAIS E MÉTODOS}

A metodologia utilizada nesse estudo se caracteriza como uma revisão integrativa de literatura, tendo um caráter exploratório, e abordagem qualitativa dos dados coletados. Buscou-se então construir uma revisão da literatura científica sobre azul de metileno e seus benefícios diante dos transtornos mentais. Foram incluídos artigos originais, disponíveis na íntegra, nos idiomas inglês e português, que abordassem a temática central acima descrita, publicados nos últimos cinco anos (2016-2021). A busca por publicações se deu nas bases de dados vinculadas à National Library of Medicine (PubMed) e à
Biblioteca Virtual em Saúde (BVS). Os descritores em ciências da saúde (DECS) utilizados napesquisa foram: methylene blue, mental disorders e neuroprotection, bem como seus termos correspondentes na língua portuguesa. A busca nas bases de dados utilizou o cruzamento dos descritores acima com o operador booleano "AND". Verificou-se que, conforme ano de publicação entre 2016 e 2021, a base de dados PubMed resultou em 11 artigos, já a BVS tiveram apenas 2 publicações. A análise desse material coletado se deu por uma análise superficial do conteúdo, onde foram analisadas similaridades e abordagens "chave" para englobar categorias temáticas para discussão. Posteriormente a análise foram estruturadas duas categorias principais: "Ação terapêutica do azul de metileno" e "Azul de metileno como tratamento nos transtornos mentais". Nesse processo de seleção das publicações através da leitura dos títulos e resumos foram eliminados dois artigos da base de dados PubMed e um artigo da base BVS, pois, no caso do PubMed não abordavam as categorias principais citadas acima e nem tinham como tema central: azul de metileno, transtornos mentais e doenças neurodegenerativas. Já no caso dos artigos da BVS um dos artigos não foi encontrado para ser baixado e estudado. Esse trabalho se trata de uma revisão de literatura, baseada em dados secundários dispensando sua submissão ao Comitê de Ética em Pesquisa de acordo com a Resolução 466/12 do Conselho Nacional de Saúde (CNS), no entanto todos os preceitos éticos foram respeitados, garantindo a legitimidade das informações, respeito aos direitos autorais, assim como uma análise imparcial dos dados coletados na literatura.

\section{RESULTADOS E DISCUSSÃO}

Após busca criteriosa nas bases literárias já citadas, foram selecionados dez estudos para discussão. Observou-se que as várias ações do azul de metileno dava-se por vários mecanismos de ação, nos quais podemos citar: à inibição da monoamina oxidase; efeito sobre a transdução de sinal neuronal; participação no metabolismo energético, na função mitocondrial e no mecanismo redox; ligação e ativação da bomba de Cálcio da Membrana Plasmática (PCMA), que está prejudicada na DA (ALDA, 2019; BERROCAL et al., 2018). O MB e um de seus metabólitos, o azure $\mathrm{B}$, tem ação inibitória sobre à enzima monoaminaoxidase (MAO). Eles inibem de maneira reversível a MAO-A e inibe de maneira mais fraca a MAO-B, podendo causar uma síndrome serotoninérgica em pacientes que estão em uso de antidepressivos inibidores da MAO. Estudos que confirmam esse achado, indicam que o uso de MB por via oral não incide riscos de síndrome serotoninérgica em pacientes em uso de medicamentos serotoninérgicos, por outro lado, pacientes em uso de MB por via intravenosa tem riscos da toxicidade serotoninérgica. Apesar do efeito de inibição da MAO, o efeito antidepressivo do azul de metileno não se dá por essa inibição e sim pelo efeito bioquímico de redução de compostos oxidativos (ALDA, 2019). Os efeitos do MB na transdução de sinal neuronal se dão pela inibição da enzima óxido nítrico sintetase (NO sintetase) que a partir da L-arginina produz óxido nítrico (NO), esse composto inorgânico ao ser produzido no neurônio pós-sináptico, ultrapassa a membrana plasmática e em uma ação retrograda, volta para o citoplasma do neurônio pré-sináptico ativando a enzima guanilato ciclase que catalisa a reação que produz o guanosina monofosfato cíclico (cGMP). O cGMP induz a liberação do neurotransmissor glutamato na fenda sináptica. $\mathrm{O}$ glutamato se liga ao receptor NMDA (N-metil-D-aspartato) no neurônio pós-sináptico, que promove abertura de canais e permite a entrada de cálcio $\left(\mathrm{Ca}^{2+}\right)$ no citoplasma do neurônio pós-sináptico. $\mathrm{O} \mathrm{Ca}^{2+}$ se liga à calmodulina e essa interação do cálcio e a calmodulina ativam o NO sintetase que produz NO neuronal. O NO produzido repete a ação retrograda, repetindo o ciclo. Em uma lesão cerebral, que resulta em uma destruição do neurônio, há uma grande liberação de glutamato, induzindo uma produção exacerbada de NO neuronal. Em grandes quantidades o NO neuronal reage com oxigênio molecular e com superóxidos $\left(\mathrm{O}_{2}^{-}\right)$, produzindo o peroxinitrito (OONO) que é um agente neurotóxico (QUEIROZ, 1999). Uma vez que o azul de metileno inibe a produção exacerbada de oxido nítrico, ele diminui a quantidade de peroxinitrito e a consequente neurotoxidade desse produto. Acredita-se que isso gere o efeito antidepressivo do azul de 
metileno. Em um estudo com cobaias, foi aplicado um composto tóxico para células dopaminérgicas, o 1-meti4-fenil-1,2,3,6-tetrahidropiridina, gerando nessas cobaias um quadro semelhante a Doença de Parkinson. Quando se aplicava nessas cobaias o azul de metileno antes da aplicação do composto tóxico, notou-se que o azul de metileno neutralizava parcialmente a ação do 1-metil-4-fenil1,2,3,6-tetra-hidropiridina e ainda aumentava a produção do fator neurotrófico derivado do cérebro (BDNF) que está ligado a sobrevivência e diferenciação neuronal (ALDA, 2019). Segundo Alda (2019) a participação do azul de metileno no metabolismo energético celular, se dá pela capacidade redox dessa substância. Na mitocôndria onde acontece grande parte da produção de ATP da célula, o azul de metileno funciona como um aceptor de elétrons, dessa maneira há uma diminuição de espécies reativas de oxigênio dentro da célula. Esse mecanismo é uma das maneiras de neuroproteção do MB pois diminui fatores oxidativos que geram danos celulares. Ao receber elétrons do NADPH, o azul de metileno se torna o azul leucometileno, que por sua vez é um doador de elétrons. Essa capacidade de aceptor e doador de elétrons, na dosagem correta, faz desse composto uma forma terapêutica na metemoglobinemia. Em aplicação de altas dosagens de azul de metileno, há grande formação de azul leucometileno, um composto pró-oxidante e doador de elétrons, podendo causar a metemoglobinemia ao invés de tratá-la. A formação do azul leucometileno é dependente do NADPH que é formado pela ação da glicose-6-fosfato desidrogenase, em pacientes com deficiência de glicose-6-fosfato desidrogenase (G6PD), ao se ministrar o azul de metileno não haverá formação de azul de leucometileno nas hemácia e consequentemente haverá aumento da concentração do azul de metileno e estresse oxidativo dentro da hemácia gerando hemólise (ALDA, 2019). Estudo realizado por Li et al. (2017) visava avaliar o uso do azul de metileno em modelos de DA a fim de analisar o efeito terapêutico do MB ao diminuir a produção de espécies reativas de oxigênio (ROS) que eram geradas na cadeia de transferência de elétrons dentro das mitocôndrias. A produção de ROS na respiração celular leva um aumento na disfunção mitocondrial. Essa hipótese é confirmada por Makhaeva (2019) que afirma que graças a capacidade redox do $\mathrm{MB}$, esse composto implementa um ciclo alternativo na cadeira respiratória mitocondrial. No estudo relatado por $\mathrm{Li}$ et al. (2017) foi realizado a aplicação via o intra-cerebroventricular (ICV) de estreptozotocinina (STZ) um composto que quando aplicado em cobaias via ICV, gera disfunção mitocondrial significativa, estresse oxidativo assim como um declínio metabólico, logo se consegue um modelo de alterações comportamentais e patológicas semelhantes a doença de Alzheimer.

A disfunção mitocondrial na DA gera um grande declínio metabólico energético devido a diminuição de produção de ATP. Ao se administrar azul de metileno na cobaia que teve quadro de DA induzida pela injeção ICV de STZ, mostrou-se que o MB atenua a disfunção mitocondrial gerada pelo estresse oxidativo, sendo um neuroprotetor para pacientes com DA. Segundo (LI et al., 2016). Um estudo feito sobre a ação do azul de metileno sobre a diminuição da disfunção mitocondrial do DA teve como modelo da doença de Alzheimer cobaias que teve um declínio de memória induzido por sevoflurano. A aplicação de MB como um pré-tratamento diminuiu o declínio da memória, devido a um aumento da quantidade de uma enzima chamada de enzima conjugadora de ubiquitina E2I (UBC9) que regula a proteína Drp1, relacionada a divisão mitocondrial e diminuição da disfunção mitocondrial, logo o aumento do UBC9 resulta em uma maior regulação de Drp1 e uma diminuição significativa da disfunção mitocondrial (Zheng, 2019). O inflamassoma é um complexo proteico intracelular envolvido no processo inflamatório. $\mathrm{O}$ azul de metileno inibe parcialmente a ativação de dois inflamassomas da micróglia, o NLRP3 e o NLRC4. O inflamassoma NLRP3, quando ativado, induz produção de compostos reativos de oxigênio, sendo esse complexo proteico associado a condições de graves distúrbios psiquiátricos. A inibição desses inflamassomas faz com que haja uma diminuição de citocinas pró-inflamatória, como interleucina- 6 , interleucina- $1 \beta$ e fator de necrose tumoral- $\alpha$, inibindo também apoptose celular (ALDA, 2019).
Os efeitos do azul de metileno em transtornos mentais são estudados desde a década de 70 e atualmente está sendo estudado seu efeito sobre doenças neurodegenerativas. Estudos mostram o efeito do MB e de seus metabólitos sobre a depressão e ansiedade. Estudo randomizado que durou 2 anos, analisou o uso de azul de metileno em pacientes com transtorno bipolar. Esse ensaio foi realizado utilizando um grupo de pacientes que receberam a dose plena do azul de metileno (300mg) e um grupo controle, que receberam uma baixa dose de azul de metileno $(15 \mathrm{mg})$. O controle não recebeu o placebo usual devido a modificação da cor da urina dos pacientes que usam o $\mathrm{MB}, \operatorname{logo}$, para se ter um ensaio de caráter duplo-cego, foi necessário que no placebo do grupo controle houvesse uma quantidade mínima de azul de metileno. Esse estudo evidenciou melhora clínica nos episódios depressivos nos pacientes que receberam a dose plena de MB obtendo também uma diminuição do número de internações. Foi destacado a melhoria nos episódios depressivos e não nos episódios de mania. Esse efeito terapêutico do MB em transtorno bipolar, em que há melhoria em episódios depressivos e a falha terapêutica sobre episódios de mania é confirmado em outro estudo que visava ver o efeito do azul de metileno em pacientes em episódio de mania. Esses mesmos pesquisadores realizaram uma pesquisa em pacientes com transtorno depressivo grave, onde se deu uma baixa dose de azul de metileno $(15 \mathrm{mg})$ para um grupo e placebo neutro para o grupo controle. O grupo que recebeu a baixa dose de MB apresentou melhoras significativas em comparação ao grupo que recebeu placebo (ALDA, 2019). Alguns outros estudos estão sendo conduzidos afim de comprovar a ação do azul de metileno sobre doenças psiquiátricas de esquizofrenia com quadros de psicose. Mostrou-se resultados ambíguos, necessitando portando de mais estudos da ação terapêutica nessa patologia. Porém o uso do azul de metileno como coadjuvante de antipsicóticos usuais mostraram uma leve melhoria nos quadros dos pacientes, sendo necessário mais ensaios clínicos dessa natureza. Estudos do $\mathrm{MB}$ no tratamento de pacientes com transtorno psicológico de claustrofobia e em pacientes com transtorno de estresse pós-traumático obtiveram resultados promissores. Os pacientes com claustrofobia apresentaram escores menores de medo, efeito terapêutico que se manteve por mais de um mês após o fim do estudo. Já no estudo com pacientes com transtorno de estresse pós-traumático, aqueles do grupo que receberam o $\mathrm{MB}$ junto com treinamento psicológico mostram melhora moderada em três meses de tratamento, quando comparados aos pacientes que estavam recebendo placebo e tratamento psicológico (ALDA, 2019).

Estudos que visavam o efeito neuroprotetor do MB foram conduzidos em caráter pré-clinico em condições especiais sendo os resultados limitados devido ao pequeno grupo de amostra. Foram analisados o efeito do azul de metileno em pacientes com lesão cerebral traumática, acidente vascular cerebral, lesão de reperfusão após isquemia cerebral e em modelos animais de DA e DP. Houve também estudos realizados com camundongos com depressão induzida por lipopolissacarídeos que demonstrou o rápido efeito neuroprotetor do MB (ALDA, 2019; YIN et al., 2018). Sabe-se que a DA é a demência que é mais prevalente em idosos. A fisiopatologia da DA é marcada pela deposição de agregados extracelulares de fragmentos de proteínas $\beta$-amiloide $(\mathrm{A} \beta)$ e na parte intracelular dos neurônios há o deposito da proteína tau hiperfosforilada, formando novelos neurofibrilares chamados também de emaranhados neurofibrilares. As presenças desses depósitos geram alterações que levarão a demência. Uma alteração a ser destacada nesse trabalho é a perca da homeoestase do $\mathrm{Ca}^{2+}$ intracelular neuronal. A desregulação do $\mathrm{Ca}^{2+}$ contribui para a progressão da DA pois está associada à disfunção das sinapses uma vez que o aumento desse íon no citoplasma neuronal estimula a produção e depósito de $A \beta$. A presença de $A \beta$ inibe a atividade da PMCA, proteína de membrana que tem como função bombear o cálcio para fora do neurônio. Essa inibição se dá pela ligação da $A \beta$ na cauda C-terminal da PMCA. O estudo feito por Berrocal et al. (2018) demonstrou que o azul de metileno se liga à cauda $\mathrm{C}$-terminal do PCMA mudando a conformação dessa bomba e a ativando, induzindo o seu funcionamento normal. $\mathrm{O}$ estudo ainda mostrou que o MB tem a capacidade de se ligar com a cauda C-terminal da PCMA e com a A $\beta$ no mesmo momento. A ação do azul de metileno se deu apenas na PCMA e não em outras bombas de cálcio pois o que diferencia a 
PCMA das outras bombas de cálcio presente na membrana celular do neurônio é justamente a cauda C-terminal mais longa (BERROCAL et al., 2018). Segundo Zhao (2020) o azul de metileno ainda inibe a agregação da proteína tau tendo efeito terapêutico na doença de Alzheimer. O azul de metileno quando fotoexcitado inibe fortemente $\mathrm{A} \beta$, pois sob iluminação adequada o $\mathrm{MB}$ tem capacidade de oxidar o peptídeo A $\beta$ (LEE et al., 2017). O uso de azul de metileno em cobaias em que se induziu um modelo de DA mostrou-se uma diminuição de depósito e agregação da proteína $\beta$-amiloide e bloqueio do depósito de proteína tau hiperfosforilada no cérebro das cobaias. Em um ensaio clínico que testou o MB em 321 pacientes com quadro leve e moderado da DA, foi-se administrado doses de $69 \mathrm{mg}, 138 \mathrm{mg}$ e $228 \mathrm{mg}$ diariamente. Após 24 semanas do início do estudo notou-se melhora nos pacientes que estavam recebendo a dose de $138 \mathrm{mg}$ de azul de metileno, os efeitos positivos se mantiveram até o final das 50 semanas em que durou o estudo. Os pacientes que receberam a dose de $69 \mathrm{mg}$ e de $228 \mathrm{mg}$ de azul de metileno não obtiveram nenhuma melhora no quadro clínico característico do DA (ALDA, 2019).

\section{CONCLUSÃO}

O presente estudo evidenciou a grande variedade de efeitos terapêuticos do azul de metileno devido às suas diversas propriedades bioquímicas, tornando o estudo da ação terapêutica desse composto desafiadora. Os efeitos do azul de metileno que merecem uma maior atenção são: suas ações neuroprotetoras através da inibição da alta produção de NO neuronal; sua ação de aceptor de elétrons na respiração celular; a ativação da PCMA, inibição da agregação da proteína tau e oxidação de proteínas $\mathrm{A} \beta$ em pacientes com DA. Notou-se que o uso do $\mathrm{MB}$ em doenças psiquiátricas e doenças neurológicas teve ações benéficas em alguns desses transtornos, principalmente quando usado como um tratamento complementar. A pouca quantidade de estudos sobre esse corante como um possível medicamento para doenças psiquiátricas mostra o desinteresse de empresas farmacêuticas em comercializar esse composto devido seu baixo custo, porém, mesmo que em pouca quantidade, os estudos demonstram a forte ação desse composto como forma terapêutica para diversas doenças, devendo, assim, ser mais estudado pela comunidade científica.

\section{REFERÊNCIAS}

ALDA, M. Methylene Blue in the Treatment of Neuropsychiatric Disorders. CNS Drugs. Aug;33(8):719-725,2019.

ALDA, M.; MCKINNON, M.; BLAGDON, R.; GARNHAM, J.; MACLELLAN, S.; O'DONOVAN, C.; HAJEK, T.; NAIR, C.; DURSUN, S.; MACQUEEN, G. Methylene blue treatment for residual symptomsof bipolar disorder: randomised crossover study. Br J Psychiatry. Jan;210(1):54-60,2017.
AMERICAN PSYCHIATRIC ASSOCIATION (ED.). Diagnosticand statistical manual of mental disorders: DSM-5. 5th ed ed. Washington, D.C: American PsychiatricAssociation, 2013

AMERICAN PSYCHIATRIC ASSOCIATION (ED.). Diagnostic and statisticalmanual of mental disorders: DSM-5. 5th ed ed. Washington, D.C: American PsychiatricAssociation, 2013.

BERROCAL, M.; CORBACHO, I; GUTIERREZ-MERINO, C.; MATA, A. M. Methylene blue activatesthe PMCA activity and cross-interactswithamyloid $\beta$-peptide, blocking $A \beta$-mediated PMCA inhibition. Neuropharmacology. Sep 1;139:163-172,2018.

LEE, B.I.; SUH, Y.S.; CHUNG,Y.J.; YU, K.; PARK, C. B. Shedding Light onAlzheimer's $\beta$-Amyloidosis: PhotosensitizedMethylene Blue Inhibits Self-Assembly of $\beta$-Amyloid Peptidesand Disintegrates Their Aggregates. Sci Rep. Aug 8;7(1):7523,2017.

LI, L.; QIN, L.; LU, H. L.; LI, P. J.; SONG, Y. J.; YANG, R. L. Methylene blue improves streptozotocin-inducedmemory deficitbyrestoring mitochondrial function in rats. Brain Res. Feb15;1657:208-214,2017.

MAKHAEVA, G. F.; SHEVTSOVA, E. F.; BOLTNEVA, N. P.; LUSHCHEKINA, S. V.; KOVALEVA, N. V.; RUDAKOVA, E. V.; BACHURIN, S. O.; RICHARDSON, R. J. Overview of novel multifunctional agentsbasedonconjugates of $\gamma$-carbolines, carbazoles, tetrahydrocarbazoles, phenothiazines, andaminoadamantanes for treatment of Alzheimer'sdisease. ChemBiol Interact. Aug1; 308:224-234, 2019.

QUEIROZ, S. L.; BATISTA, A. A. Funções biológicas do óxido nítrico. Quím. Nova, São Paulo, v. 22, n. 4, pág. 584-590, julho de 1999.

SMITH, E. S.; CLARK, M. E.; HARDY, G. A.; KRAAN, D. J.; BIONDO, E.; GONZALEZ-LIMA, F.; CORMACK, L.; K.; MONFILS, M.; LEE, H.; J. Daily consumption of methylene blue reducesattentional deficitsanddopaminereduction in a 6OHDA model of Parkinson'sdisease. Neuroscience, 359, 8-16, 2017.

YIN, S.; SHAO, J.; WANG, X.; YIN, X.; LI, W.; GAO, Y, VELEZ DE-LA-PAZ, O. I.; SHI, H.; LI, S. Methylene blue exertsrapidneuroprotective effects onlipopolysaccharideinducedbehavioraldeficits in mice. BehavBrain Res. Jan $1 ; 356: 288-294,2019$.

ZHAO, J.; YIN, F.; JI, L.; WANG, C.; SHI, C.; LIU, X.; YANG, H.; WANG, X.; KONG, L.Developmentof a Tau-TargetedDrug Delivery System Using a MultifunctionalNanoscale MetalOrganic Framework for Alzheimer'sDiseaseTherapy. ACS ApplMater Interfaces. Oct 7;12(40):44447-44458, 2020

ZHENG, F.; FANG, P.; CHANG, J.; CHEN, M.; ZHONG, Q.; CHEN, T.; CHEN, C.; ZHANG, Z. Methylene Blue Protects Against Sevoflurane-Induced Cognitive Dysfunction by Suppressing Drp1 deSUMOylation in AgedMice. Neurochem Res. Apr;45(4):956963,2020 